Thorax (1946), 1, 263.

\title{
ATELECTASIS AS A COMPLICATION OF PULMONARY LOBECTOMY
}

BY

\author{
IAN R. GRAY \\ Thoracic Unit, Horton War Hospital
}

Lobectomy has been established as the correct surgical treatment for many pathological conditions and the dangers of the operation have been reduced to reasonable proportions; but post-operative atelectasis still occurs, and the problem of its cause and management remains to be solved. The figures which have been published give rates of atelectasis after lobectomy for bronchiectasis varying from 10 per cent to 40 per cent (Gowar, 1941 ; Belsey, 1937 ; Maier, 1944 ; Sellors, 1944). These cases of atelectasis can be divided into "temporary," in which the lobe re-expands in a few days, and "permanent," in which a progressive pneumonitis occurs in the atelectatic lobe. Permanent atelectasis of the remaining lobe after a lobectomy leaves the patient very much worse off than before operation. It may lead either to persistent low-grade infection, or to virulent suppuration which may rapidly kill the patient. Nine out of the fourteen cases of permanent atelectasis described by Gowar (1941) died. Even when permanent atelectasis does not ensue, patients with temporary atelectasis do not progress as well as those in which the remaining lobe expands immediately after the operation to fill the hemithorax. Delay in re-expansion increases the likelihood of empyema, and the occurrence of intra-pleural complications predisposes to atelectasis. Hence, the rate of "imperfect results" is 23 per cent after lobectomies where there has been a temporary atelectasis, compared with 11 per cent where the lobe has remained aerated (Sellors, 1944).

After abdominal operations, atelectasis is generally patchy rather than lobar or total (Mimpriss and Etheridge, 1944 ; Lucas, 1944), but after lobectomy it is often massive. The reason is that additional causative factors operate. The most important of these are the presence of mucopurulent secretions in the bronchial tree, open pneumothorax during the period of operation, and manipulation of the lung. These factors operate on the whole of the portion of the lung which is not removed. Minor degrees of patchy atelectasis occur as well as massive atelectasis, but are often difficult to detect in radiographs taken during the first few days after lobectomy. Thus, atelectasis which can be diagnosed with certainty after lobectomy nearly always involves an entire lobe.

Lobar atelectasis with bronchial obstruction generally becomes evident clinically in the first week after operation. The diagnosis is straightforward and depends on the presence of mucopurulent sputum-often coughed up with 
considerable difficulty-fever, and tachycardia. The sputum becomes copious as the condition progresses, and the predominant organisms are usually pneumococci. The fever is less striking than in atelectasis after a non-pulmonary operation. Examination of the chest shows absent or bronchial breath-sounds over the remaining lobe, and rales may be heard. Displacement of the mediastinum cannot be regarded as a reliable sign, useful though the indication may be after other operations. The diagnosis is established by radiography; the typical appearance is of an airless lobe collapsed on the mediastinum. Pleural adhesions are seen as bands stretching across a pneumothorax from the collapsed lobe to the chest wall. The picture may be obscured by the presence of fluid in the pleura: this may have to be aspirated, particularly after an upper lobectomy, before the condition of the lung can be seen. Routine radiographs should always be taken during the first two days after a lobectomy so that a collapsed lobe may be detected and treatment begun before signs such as fever and sputum become obvious.

Bronchial obstruction, with atelectasis of the remaining lobe as a complication, usually occurs soon after lobectomy, and if the condition persists it is almost certain to be complicated by suppurative pneumonitis. If this sequence of events is not interrupted the infection may become permanent, but if the atelectatic lobe becomes aerated sufficiently soon recovery can take place.

\section{Analysis of 106 Cases of Pulmonary lobectomy}

An unselected series of 106 cases of pulmonary lobectomy performed in the Thoracic Unit at Horton War Hospital between March, 1941, and February, 1945, by four different surgeons, has been examined to determine the incidence of post-operative atelectasis and to evaluate statistically the factors contributing to its occurrence. All the lobectomies were performed under general anaesthesia with an endotracheal tube in place. Controlled respiration was used only when indicated, and tracheo-bronchial suction was frequently carried out to remove bronchial secretions. The principal agents employed were cyclopropane and ether. Pleural adhesions were induced pre-operatively in a large number of cases by poudrage with kaolin or by intra-pleural instillation of silver nitrate.

In this series there were 23 cases of lobe atelectasis occurring in the immediate post-operative period. Of these, 22 were of one of the remaining lobes on the side of the operation, and there was one case of contralateral atelectasis of the lower lobe. In addition, there was one case of contralateral atelectasis which occurred two months after operation. The latter has not been included in the figures, as the period after operation was too long for its cause to be assigned. Of the 23 cases of atelectasis, 3 became permanent.

The cases of atelectasis were analysed to determine the significance of several suspected factors. Some of these have been analysed by previous writers. The 
presence of pleural adhesions has been found by most writers to diminish the incidence of post-operative atelectasis. Although Chesterman (1943) condemns pre-operative pleurodesis and suggests that adhesions cause distortion and atelectasis of the remaining lobe, he gives no figures to substantiate this view, and the consensus of opinion is at present against it. Other writers emphasize the value of pre-operative pleurodesis, and their figures are impressive: 48.6 per cent rate of atelectasis without adhesions, compared with 20.3 per cent occurrence with adhesions present (Gowar, 1941) ; 42 per cent compared with 22 per cent (Sellors, $1944)$ and 11 per cent compared with none (Maier, 1944).

Belsey (1937) emphasized the importance of the time interval between bronchography and lobectomy and showed the incidence of lobar atelectasis to be 17 per cent where the interval between the latest bronchogram and operation was more than eight weeks, as compared with 60 per cent where it was less. It has been suggested that the presence of bronchiectasis in the remaining lung tissue is conducive to atelectasis after operation (Maier, 1944) but the Brompton Hospital figures do not support this view (Belsey, 1937 ; Gowar, 1941).

Local, inhalation, and spinal anaesthesia are followed by the same incidence of atelectasis (Belsey, 1937), and Belsey (1937) reported that the quantity of sputum coughed up before operation made no difference. The removal of the lingula has been suggested as a cause of atelectasis of the left upper lobe: it has been considered to produce bronchial obstruction by oedema of the tissues adjacent to the stump of the lingular bronchus (de Goycoechea, 1944). Other factors may be the general condition of the patient, adequacy of pleural drainage, and efficient breathing exercises before and after operation.

Most of the lobectomies in this series were performed for bronchiectasis, but several were for other conditions. The incidence of atelectasis according to the nature of the disease was calculated, as was the incidence attributable to pleural adhesions and the duration of drainage. Analyses were made of the sex and age of the patients, and the extent of the operation. The season of the year, the amount of sputum, and the presence of sinus infection before operation were also investigated. A study was made of the incidence of empyema in cases of

TABLE I

NATURE OF THE DISEASE

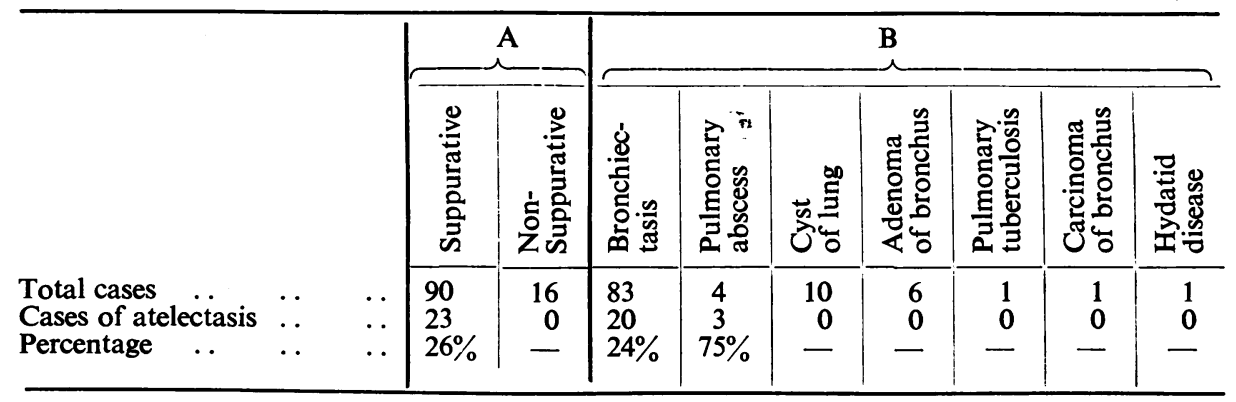


atelectasis. Neither the time interval between bronchography and lobectomy, nor details of anaesthesia, have been considered.

Table I suggests that, whilst atelectasis occurs frequently after the removal of a bronchiectatic lobe, it is unusual after a lobectomy for a non-suppurative process. In both bronchiectasis and lung abscess the bronchi have been subjected to contact with highly infected material for long periods. Furthermore, at the time of operation, however early the bronchial clamp may be applied, there is some risk of pus being squeezed out of the diseased lobe as it is manipulated, and of this pus passing into the remainder of the bronchial tree. In these cases both factors may be operative, and in addition the bronchial mucosa in the remainder of the lung may be chronically inflamed, and the bronchus more easily obstructed than normally.

TABLE II

THE EFFECT OF PLEURAL ADHESIONS

\begin{tabular}{|c|c|c|c|c|c|c|}
\hline \multirow[b]{2}{*}{$\begin{array}{c}\text { Adhesions } \\
\text {. }\end{array}$} & \multicolumn{4}{|c|}{ A } & \multicolumn{2}{|c|}{ B } \\
\hline & None & + & ++ & +++ & $\begin{array}{c}\text { Some } \\
\text { adhesions }\end{array}$ & $\begin{array}{c}\text { No } \\
\text { adhesions }\end{array}$ \\
\hline $\begin{array}{l}\text { Total cases* } \\
\text { Cases of atelectasis } \\
\text { Percentage ... .. }\end{array}$ & $\begin{array}{c}24 \\
9 \\
38 \%\end{array}$ & $\begin{array}{l}17 \\
2 \\
12 \%\end{array}$ & $\begin{array}{c}46 \\
7 \\
15 \%\end{array}$ & $\begin{array}{c}11 \\
1 \\
9 \%\end{array}$ & $\begin{array}{l}74 \\
10 \\
14 \%\end{array}$ & $\begin{array}{c}24 \\
9 \\
38 \%\end{array}$ \\
\hline
\end{tabular}

* Eight cases omitted as records were inadequate.

Previous reports have suggested the value of pleural adhesions in preventing atelectasis after lobectomy. In the majority of the cases of suppurative disease an attempt was made to induce a pneumothorax before operation. If this was possible, poudrage or instillation of silver nitrate followed. It was found that poudrage with kaolin or iodized talc was the most effective method, as the instillation of silver nitrate had often to be repeated before a satisfactory reaction was obtained, whereas poudrage produced adhesions in every case at the first attempt.

The pleural adhesions found at operation were classified in three groups. + represents a few fine strands, ++ indicates firm adhesions over the lung, and +++ indicates many tough adhesions which caused considerable inconvenience to the surgeon. Table II, which includes all types of disease, shows a difference

TABLE III

DURATION OF POST-OPERATIVE DRAINAGE

OF THE PLEURAL CAVITY

\begin{tabular}{l|c|c|c}
\hline & $\begin{array}{c}\text { No } \\
\text { drainage }\end{array}$ & $\begin{array}{c}\text { Temporary } \\
\text { drainage }\end{array}$ & $\begin{array}{c}\text { Tube } \\
\text { left in }\end{array}$ \\
\cline { 2 - 4 } $\begin{array}{l}\text { Total cases } \\
\begin{array}{l}\text { Cases of atelectasis } \\
\text { Percentage }\end{array}\end{array}$ & 27 & 54 & 25 \\
\hline
\end{tabular}


between those which had some pleural adhesions and those with none, thus confirming previous reports. The quality of adhesions appears to be of less significance.

In most of these lobectomies closed drainage of the pleura was established at the end of the operation, the drainage tube being led to an under-water seal. Three groups were compared. In the first the chest was closed without drainage. The second group were drained for 72 hours or less. In the last, the tube was left in and pleural infection supervened. It was in this group that the rate of atelectasis might have been expected to be highest. The difference in the incidence of atelectasis in these three groups cannot be regarded as significant, nor can post-operative drainage be regarded as contributing to the occurrence of atelectasis (Table III).

TABLE IV

THE EXIFNT OF THE OPERATION

\begin{tabular}{|c|c|c|c|c|c|c|c|c|c|c|c|c|}
\hline \multirow[b]{2}{*}{ Lobe removed } & \multicolumn{9}{|c|}{ A } & \multicolumn{3}{|c|}{ B } \\
\hline & ند & 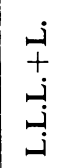 & نَّ & $\begin{array}{l}\dot{j} \\
\dot{+} \\
\dot{\dot{x}} \\
\dot{\alpha}\end{array}$ & $\stackrel{\dot{\sum}}{\dot{\sum}}$ & ذبـد & \begin{tabular}{l|}
$\dot{\dot{a}}$ \\
$\dot{\alpha}$
\end{tabular} & $\begin{array}{l}\stackrel{\dot{j}}{\Sigma} \\
+ \\
\dot{\Sigma} \\
\dot{\alpha}\end{array}$ & 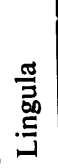 & $\begin{array}{l}0 \\
.00 \\
\dot{20}\end{array}$ & 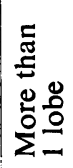 & $\begin{array}{l}\bar{\Xi} \\
0 \\
\Leftrightarrow\end{array}$ \\
\hline $\begin{array}{ll}\text { Total cases } & \ldots \\
\text { Cases of atelectasis } & \ldots \\
\text { Percentage } & \ldots\end{array}$ & $\begin{array}{l}30 \\
6 \\
20 \%\end{array}$ & $\begin{array}{c}18 \\
4 \\
22 \%\end{array}$ & $\begin{array}{c}13 \\
1 \\
8 \%\end{array}$ & $\begin{array}{c}23 \\
7 \\
30 \%\end{array}$ & $\begin{array}{c}11 \\
3 \\
27 \%\end{array}$ & $\begin{array}{c}3 \\
1 \\
33 \%\end{array}$ & $\begin{array}{l}2 \\
0 \\
-\end{array}$ & $\begin{array}{l}3 \\
1 \\
33 \%\end{array}$ & $\begin{array}{l}3 \\
0 \\
-\end{array}$ & $\begin{array}{l}62 \\
11 \\
18 \%\end{array}$ & $\begin{array}{l}44 \\
12 \\
27 \%\end{array}$ & $\begin{array}{l}106 \\
23 \\
22 \%\end{array}$ \\
\hline
\end{tabular}

The cases were analysed according to the portions of the lung removed (Table IV). Atelectasis of the upper lobe was found to be appreciably more common after left than after right lower lobectomy. This has been described before (Gowar, 1941). Removal of the lingula as well as the lower lobe caused an insignificant increase in the occurrence of atelectasis of the upper lobe, whereas removal of the right middle in addition to the right lower lobe had an influence on the figures. If the cases in which a single lobe was removed are compared with those in which two lobes, or the lower lobe and lingula, were removed, there is a suggestive difference. Whether this is due to the length of operation and increased handling of hilar structures with risk of spill of secretions to the "good" lobe, or to the greater volume of lung excised, cannot be stated.

Three age groups were studied (Table V). The first were children up to the age of 16 . The second were adolescents and young adults between the ages of 16 and 30 . The third were over 30 . In 24 lobectomies in children the rate of atelectasis was 38 per cent. In the two older groups the rates were 18 per cent and 19 per cent respectively. The proportion of children who were found to have pleural adhesions at operation was approximately the same as in the entire series; but there was a preponderance of cases of bronchiectasis in this group. 
TABLE $V$

OCCURRENCE OF ATELECTASIS IN DIFFERENT AGE GROUP ;

\begin{tabular}{|c|c|c|c|c|c|}
\hline \multirow[b]{2}{*}{ Age .. } & \multicolumn{3}{|c|}{ All cases } & \multicolumn{2}{|c|}{$\begin{array}{l}\text { Cases of } \\
\text { suppurative } \\
\text { disease }\end{array}$} \\
\hline & $0-15$ & $16-30$ & $31+$ & $0-15$ & $16+$ \\
\hline $\begin{array}{l}\text { Total cases } \\
\text { Cases of atelectasis } \\
\text { Percentage .. }\end{array}$ & \begin{tabular}{|c|}
24 \\
9 \\
$38 \%$
\end{tabular} & \begin{tabular}{|l|}
55 \\
10 \\
$18 \%$
\end{tabular} & $\begin{array}{l}27 \\
5 \\
19 \%\end{array}$ & $\begin{array}{l}22 \\
9 \\
41 \%\end{array}$ & $\begin{array}{l}60 \\
14 \\
23 \%\end{array}$ \\
\hline
\end{tabular}

The cases of suppurative disease were then investigated according to age, and it was found that the high rate of atelectasis was still present amongst the children. It has been suggested that lack of co-operation on the part of the patient in coughing and breathing deeply during the rather painful post-operative phase contributes to the causation of atelectasis (Lucas, 1944). This is a possible factor, but as the children had been in the hospital for a considerable time, and were often more co-operative than their elders, and usually complained of less pain after the operation, this should not be over-stressed. A probable cause of the higher rate of atelectasis is the smaller diameter of the bronchi in children.

TABLE VI

INFECTION OF THE PARA-NASAL AIR SINUSES BEFORE OPERATION

\begin{tabular}{|c|c|c|c|c|}
\hline \multirow[b]{2}{*}{ Condition of antra } & \multicolumn{2}{|c|}{ All Cases } & \multicolumn{2}{|c|}{$\begin{array}{c}\text { Cases of } \\
\text { Suppurative } \\
\text { Disease }\end{array}$} \\
\hline & Infected & Clean & Infected & Clean \\
\hline $\begin{array}{l}\text { Total cases ... } \\
\text { Cases of atelectasis } \\
\text { Percentage ... }\end{array}$ & $\begin{array}{c}23 \\
8 \\
35 \%\end{array}$ & $\begin{array}{l}83 \\
15 \\
18 \%\end{array}$ & $\begin{array}{c}21 \\
8 \\
38 \%\end{array}$ & $\begin{array}{l}69 \\
15 \\
22 \%\end{array}$ \\
\hline
\end{tabular}

The relationship between chronic infection of the nasal sinuses and bronchiectasis has often been commented upon (Mullin, 1921 ; Simonton, 1943). The chronic infection element in bronchiectasis is undoubtedly maintained by nasal infection in many cases. In this series, 23 out of 106 patients had antral infection which was treated before operation (Table VI). All antral infections were treated by puncture and washout and often by more radical procedures. In spite of this treatment, the sinus infection seldom cleared completely. The rate of atelectasis was appreciably higher in those cases in which antral disease was present. This was true both of the whole series and of the cases of suppurative disease taken separately. Nevertheless, there were two cases of non-suppurative 
disease of the lung in which there was definite antral infection before operation, and in these atelectasis did not occur.

TABLE VII

SEX INCIDENCE

\begin{tabular}{lr|l|l}
\hline & Sex & Male & Female \\
\hline \multicolumn{2}{l|}{$\begin{array}{l}\text { Total cases } \\
\text { Cases of atelectasis }\end{array}$} & 65 & 41 \\
Percentage &.. & $23 \%$ & $22 \%$ \\
\hline
\end{tabular}

It might have been expected that with the larger percentage of smokers amongst men, the incidence of atelectasis would be higher in males; but this was not the case (Table VII).

TABLE VIII

VOLUME OF SPUTUM EXPECTORATED BY THE PATIENTS BEFORE OPERATION

\begin{tabular}{|c|c|c|c|c|c|c|}
\hline \multirow[b]{2}{*}{ Amount of Sputum } & \multicolumn{3}{|c|}{ All Cases } & \multicolumn{3}{|c|}{ Cases of suppurative disease } \\
\hline & Nil & $\begin{array}{l}\text { Less than } \\
1 \mathrm{oz} .\end{array}$ & $\begin{array}{l}\text { More than } \\
1 \mathrm{oz} .\end{array}$ & Nil & $\begin{array}{c}\text { Less than } \\
1 \mathrm{oz} .\end{array}$ & $\begin{array}{c}\text { More than } \\
1 \mathrm{oz} .\end{array}$ \\
\hline $\begin{array}{l}\text { Total cases } \\
\text { Cases of atelectasis } \\
\text { Percentage } \quad . .\end{array}$ & $\begin{array}{c}15 \\
1 \\
7 \%\end{array}$ & $\begin{array}{l}55 \\
10 \\
18 \%\end{array}$ & $\begin{array}{l}36 \\
11 \\
31 \%\end{array}$ & $\begin{array}{l}11 \\
1 \\
9 \%\end{array}$ & $\begin{array}{l}44 \\
10 \\
23 \%\end{array}$ & $\begin{array}{l}35 \\
11 \\
31 \%\end{array}$ \\
\hline
\end{tabular}

All the patients in this series had prolonged treatment by postural drainage, breathing exercises, and percussion before operation. These measures brought about a considerable diminution in the amount of sputum brought up daily. In view of the possibility that pus distributed throughout the bronchial tree during operation might cause atelectasis by bronchial embolism, it was felt that there might be a relationship between the quantity of sputum coughed up daily just before operation and the occurrence of atelectasis afterwards. It was shown that patients who had no sputum before operation seldom developed atelectasis afterwards: these were virtually non-infected cases. Those coughing up sputum before operation had a higher rate of atelectasis (Table VIII).

TABLE IX

THE SEASON OF THE YEAR

\begin{tabular}{l|c|c}
\hline Season & $\begin{array}{c}\text { Summer } \\
\text { May-Oct. }\end{array}$ & $\begin{array}{c}\text { Winter } \\
\text { Nov.-April }\end{array}$ \\
\hline Total cases r.. & 58 & 48 \\
Cases of atelectasis & 11 & 12 \\
Percentage & $19 \%$ & $25 \%$ \\
\hline
\end{tabular}


Table IX shows that the occurrence of atelectasis is the same in winter and summer.

The incidence of empyema is almost twice as high in those patients who have had post-operative atelectasis of the remaining lobe as it is in those whose lobe has remained aerated (Table X). This is not surprising as the pleural cavity around an atelectatic lobe in which a suppurative pneumonitis is developing is very liable to become contaminated. Likewise the complete or even partial obliteration of the pleural cavity by the expansion of the remaining lobe after operation makes the development of an empyema less likely.

As a corollary, the series was examined to show whether the occurrence of atelectasis had any bearing upon the mortality rate. There were five deaths following operation. Only one of these occurred after atelectasis, and this patient died 22 days after operation from a secondary haemorrhage. A temporary atelectasis had occurred, and after the lobe had re-expanded, a bronchopleural fistula developed with an empyema. In the whole series of 106 cases the mortality in those cases in which atelectasis occurred was 4.3 per cent compared with 4.8 per cent in those in which there was no atelectasis.

TABLE $\mathrm{X}$

RELATIONSHIP OF ATELECTASIS TO PLEURAL INFECTION

\begin{tabular}{ll|l|c}
\hline & $\begin{array}{c}\text { Cases } \\
\text { with } \\
\text { atelectasis }\end{array}$ & $\begin{array}{c}\text { Cases } \\
\text { without } \\
\text { atelectasis }\end{array}$ \\
${ } }$ & $\ldots$ & 23 & 83 \\
Empyema & $\cdots$ & 11 & 22 \\
Percentage & $\cdots$ & $48 \%$ & $25 \%$ \\
\hline
\end{tabular}

\section{Notes on Three Cases of Failure of Re-expansion}

Of the 23 cases of atelectasis, the affected lobe re-expanded in 20 . In 10 of these there was an empyema requiring drainage and one death already mentioned; in the remainder atelectasis caused no permanent harm, and in the majority the lobe was fully aerated within a week. In 3 patients re-expansion of the lobe did not occur, and it became the seat of suppurative pneumonitis. All 18 were cases of bronchiectasis in young people. Before operation 2 were producing $1 \mathrm{oz}$. sputum daily and 1 was producing $6 \mathrm{oz}$. One patient had bilateral disease, the right middle and lower lobes and the left lower lobe being affected, and right middle and lower lobectomy was performed. In spite of good pleurodesis, the right upper lobe became atelectatic after operation and failed to re-expand. This was a boy, aged 14, suffering from extensive bilateral disease; he was a dubious subject for operation in the first place, but atelectasis undoubtedly 
aggravated his condition. The next two had no pleural adhesions. One developed atelectasis of the right upper lobe after middle and lower lobectomy, the other developed atelectasis of the left upper lobe after left lower lobectomy. It was in the latter that there was $6 \mathrm{oz}$. sputum daily before operation. There was atelectasis of the left upper lobe with a total empyema, and a left upper lobectomy was performed six months after the first operation. The tragic results of an atelectasis which fails to re-expand are seen from these instances.

\section{ProphylaXis of Atelectasis}

At Horton War Hospital lobectomy for suppurative disease of the lung has been complicated in one case out of three by atelectasis of the remaining lobe on the side of the operation. The age at which children are operated on is of some importance. So long as the disease is not progressing, there is an argument that the risk of operation is less after they are well into their " teens." Nevertheless, the delay of mental and physical development which sometimes occurs with bronchiectasis suggests that earlier operation may be advisable.

The presence of pleural adhesions in suppurative disease reduces the incidence of atelectasis from 38 per cent to 14 per cent, and thus artificial production of adhesions with silver nitrate, iodized talc, or kaolin is beneficial. This is specially to be recommended in children, in patients where more than one lobe is to be removed, and where there is a considerable amount of sputum.

Pre-operative breathing exercises and postural drainage improve the respiratory efficiency of the lungs and diminish the quantity of sputum, and so physical therapy can be regarded as a vital part of the pre-operative prophylaxis of atelectasis.

Skilful anaesthesia is likely to diminish the incidence of lobar atelectasis, although the agent itself is not of great importance. The maintenance of a clear airway, and the removal of secretions by tracheo-bronchial aspiration during operation are important in my view, but some authorities believe that the latter may actually produce atelectasis. Normal ventilation of the lung may cause impaction of secretions in the smaller bronchi, but this has not been proved. There are techniques by which the diseased lobe can be plugged off, or its secretions aspirated by means of an indwelling catheter; these are worth considering where the risk of atelectasis is great. The absorption of gases from a lobe whose bronchus is blocked may be a factor in the development of atelectasis. For this reason air should be mixed with the anaesthetic mixture during operation, because, if the lobe contains some non-absorbable gas at the time of bronchial occlusion, total atelectasis may be delayed and perhaps prevented.

Surgically, the prevention of lobar atelectasis can be assisted by assuring that, during the operation, the diseased lobe is handled as gently as possible. The bronchus to the affected lobe should be clamped or tied at an early stage, so that spilling of pus from the diseased to the healthy parts of the bronchial tree is 
minimized. The healthy portion of the lung should also be handled carefully and kept fully aerated throughout.

During the first few days after operation the patient should be encouraged to cough and to breathe deeply (Waters, 1940). He should be rolled from side to side, and the foot of the bed raised for periods during the day to assist the coughing-up of bronchial secretions. Tight binders should be avoided, and the utmost freedom of movement should be permitted.

The post-operative use of depressant drugs has often been condemned, but retention of secretions leading to atelectasis is likely to occur only when very large doses are used. On the contrary, without these drugs, coughing is likely to be too painful to allow secretions to be expectorated. It is necessary to strike a happy medium. A moderate injection of morphia, $\frac{1}{6}$ to $\frac{1}{4} \mathrm{gr}$. (10 to $15 \mathrm{mg}$.) for an adult, should be given at intervals during the day, perhaps half an hour before breathing exercises and rolling are to be done. Sufficient analgesia is then afforded to obtain adequate co-operation from the patient (Brock, 1936). The injection of the intercostal nerves with a long-acting local analgesic at the end of the operation also allows the patient to cough up secretions without much pain.

Inhalations of carbon dioxide are often administered as a prophylactic measure against atelectasis. It has been stated that carbon dioxide is a most effective expectorant and is useful in that way as well as increasing the depth of respiration (Holinger, 1941). The latter effect is undeniable, but it is of questionable value in some cases, because the deep breathing induced by inhalations of carbon dioxide may assist in the aspiration of secretions rather than in their expectoration (Brock, 1936). Carbon dioxide should be administered only to patients whose breathing is unduly shallow, and in whom the bases of the lungs are not being aerated adequately. In others it is unnecessary.

\section{Treatment of Atelectasis}

The importance of early diagnosis cannot be emphasized too strongly. The patients should be examined clinically at least once daily after a lobectomy, and radiographs on the first and second days are essential. The house officer should also watch the quantity and nature of the sputum, the pulse rate, and temperature range.

At the first sign of atelectasis, postural drainage should be intensified. Most atelectatic lobes will re-expand without further treatment. If the affected lobe shows no sign of early re-expansion, or if the patient's general condition is deteriorating, more active measures must be taken. The simplest of these is " tracheo-bronchial toilet" (Waters, 1940). This procedure, which can readily be carried out in the ward, consists of tracheal intubation under local anaesthesia with suction by means of a fine catheter. This can cause immediate re-expansion, or may break the vicious circle and start the expectoration of the retained secretions; it is a simple measure and is the treatment of choice (Canfield, 1944 ; 
Nosworthy, 1944). If no benefit results, early bronchoscopy is recommended, and, indeed, some consider it the more desirable measure in the first instance (Lell, 1941 ; Adams, 1943). The administration of sulphonamides and penicillin has been recommended (Kerr, 1943), but this is generally unnecessary and ignores the essential nature of the lesion.

\section{SUMMARY}

The clinical picture of lobar atelectasis occurring after pulmonary lobectomy is described.

A series of 106 lobectomies has been analysed to determine the rate of occurrence of atelectasis and to evaluate the factors determining its occurrence. In 90 cases of suppurative disease the incidence of atelectasis was 26 per cent ; there were no atelectases after 16 lobectomies for non-suppurative conditions. The presence of pleural adhesions at the time of operation was associated with a considerably reduced incidence of post-operative atelectasis. The rate of atelectasis was increased when more than one lobe had been removed. Examining the series according to age, it was found that in children the likelihood of atelectasis was twice as great as in adults. Cases where the amount of sputum produced daily was more than $1 \mathrm{oz}$. had a higher rate of atelectasis than those with less. Factors found in this series to have no influence on the occurrence of atelectasis were the sex of the patient, the season of the year, and the duration of pleural drainage.

Three cases of permanent collapse are described. Some suggestions for the prevention of atelectasis after lobectomy are made, and the methods of treatment available are summarized.

I wish to express my thanks to Mr. C. Price-Thomas, Mr. R. C. Brock, and Mr. N. R. Barrett for permission to use records of their cases for this paper.

\section{REFERENCES}

Adams, W. B. (1943). J. Indiana med. Ass., 36, 299.

Alexander, J., and O'Rourke, P. V. (1944). Univ. Hosp. Bull. Ann. Arbor., 10, 9.

Belsey, R. H. R. (1937). Brompton Hosp. Rep., 6, 133.

Brock, R. C. (1936). Guy's Hosp. Rep., 86, 191.

Canfield, N. (1944). Proc. roy. Soc. Med., 37, 301.

Chesterman, J. T. (1943). Arch. Surg., $47,448$.

Gowar, F. J. S. (1941). Brit. J. Surg., $29,3$.

De Goycoechea, O. L. (1944). Prensa med. Arg., 31, 1,930.

Hilding, A. C. (1944). Anaesthesiology, 5, 225.

Holinger, P., et al. (1941). J. Amer. med. Ass., 117, 675.

Kerr, J. T. (1943). N.C. med. J., 4, 137.

Lell, W. A. (1941). Penn. med. J., 44. 1,551.

Lucas, B. G. B. (1944). Brit. J. Surg., 31, 288.

Maier, H. C. (1944). Surgery, 15, 789.

Marshall, J. M. (1944). Nav. med. Bull. Wash., 42, 601.

Mimpriss. T. W., and Etheridge, F. G. (1944). Brit. med. J., 2, 466.

Mullin, W. V. (1921). Ann. Otol., 30, 683.

Nosworthy, M. D. (1944). Proc. roy. Soc. Med., 37, 303.

Sellors, T. H., et al. (1944). Lancet, 2, 101.

Simonton, K. M. (1943). Ann. Otol., 52.598.

Waters, R. M. (1940). Anaesthesiology, 1, 136. 